\title{
Enhancing Employees' Digital Experience Through Internal Platform
}

\author{
Thimotius Terry Very Ervinta ${ }^{1}$, Johny Natu Prihanto ${ }^{2}$, Kristianus Ade Sudiyono ${ }^{3}$ \\ \{thimotius.terry@student.umn.ac.id¹, johny.natu@umn.ac.id², adesudiyono@gmail.com³
}

\begin{abstract}
Faculty of Management, Universitas Multimedia Nusantara, Indonesia ${ }^{1}$, Faculty of Management, Universitas Multimedia Nusantara, Indonesia ${ }^{2}$, Faculty of Management, Universitas Multimedia

Nusantara, Indonesia ${ }^{3}$
\end{abstract}

\begin{abstract}
Kompas Gramedia (KG) employees increases every year and currently transforming towards digital. Technology utilization is important to improve employee digital experience in order to increases employee performance, one of them by using an internal platform, MyKG. Digital transformation which is conducted related to some features in MyKG, such as integration of KG digital products, onboarding, and the use of QR codes. Digital transformation project (DTP) using a conceptual model of digital maturity models TM Forum \& Deloitte. DTP measure the digital maturity of current and future conditions and analyze the business capability. Interviews with stakeholders were conducted to measure current and future condition. The study recommend to developed some features in MyKG to enhance employees' digital experience. Digital roadmap was created to assist companies in carrying out digital transformation. The outcomes of this research can be used by other company who want enhance employees' digital experience through their internal platform.
\end{abstract}

Keywords: employee digital experience, internal platform, integration products, onboarding, QR codes

\section{Introduction}

The workforce in Indonesia increases every year. Indonesia is an agricultural country, which means it is very dependent on the agriculture, forestry and fisheries sectors. The development of the Indonesian economy in recent years has been marked by the emergence of several start-ups that have increased the number of formal workers in Indonesia. Most of the formal workers are in Jakarta [1].

Kompas Gramedia is a company located in Jakarta. The number of Kompas Gramedia employees always increases every year. Currently Kompas Gramedia focuses on transforming towards digital with the emergence of digital-focused business units such as Gramedia Digital Nusantara (Gramedia.com), Group of Hotels \& Resorts (MySantika), Oval (MyValue), Grid (Gridstore). However, currently there is no internal platform that unites these digital products, so employees still have to access different applications or platforms. (Internal company, 2020)

According to Tennant, there are 2 types of customers, namely internal and external. An external customer is someone who has a relationship with a company or organization, they are the end user of the product or service that the company offers. Meanwhile, internal customers are employees who interact and carry out several activities within the company [2]. With the number of employees increasing every year, Kompas Gramedia employees are potential customers for the company to market or offer its digital products. In general, according to Cook, internal customer satisfaction is generated by employee performance so that it can be said that internal customer satisfaction leads to employee performance [2]. In addition, Kennedy argued that employee performance should allow the organization to improve its orientation towards external customers [2].

Human Resources process in a company can be described into a life cycle called the Employee Life Cycle, which is the cycle of employees from starting to look for a job, applying for a job, working, and until they stop working. The employee life cycle is divided into several stages, namely attraction, recruitment, onboarding, development, retention, and separation [3]. One of the employee life cycle processes is onboarding. Onboarding is a transitional process 
where new employees are given information about the work they are going to do so that new employees quickly adapt to their work and their surroundings such as superiors and coworkers. However, currently onboarding in Kompas Gramedia still done manually by holding in-class training which is ineffective. There are still Kompas Gramedia employees who do not know what business units or business units are owned by Kompas Gramedia. Onboarding process is centralized in Palmerah so that employees outside Palmerah do not get complete information and not getting the same explanation. The large number of Kompas Gramedia employees scattered throughout Indonesia made it difficult for the onboarding process to be carried out face-to-face in the room. It is even more difficult to ask for time from the leaders who are the speakers so that there are often delays in the onboarding schedule so that onboarding cannot be carried out directly on the first day of the employee's work.

A way to improve employee digital experience in a company is to use QR codes when you want to exchange contacts with other employees. And the QR codes can also function as a presence when employees want to attend an event such as employee training.

\section{Literature Review}

\subsection{Employee Experience}

Employee experience is a sum of all interactions occurring between employees and the organization [4]. These interactions are influenced by three things, like physical space, the culture of the organization, and the tools or technology provided by the employer. The role of technology not only in automating the work but also in enhancing the employee experience [5]. Both practitioners and academicians have contributed to the idea of employee engagement and confirmed that engaged employees are more productive, committed to the organization and stay happy and healthy. Employee experience creates an engaged workforce [5].

\subsection{Digital Maturity Model}

Digital Maturity Model (DMM) framework used is the Deloitte - TM Forum which is a standardized assessment tool or framework to measure digital maturity in an industry or a company. There are 5 main dimensions divided into 28 sub-dimensions and 179 criteria for measuring digital maturity. There are 5 levels of digital maturity, namely initiating, emerging, performing, advancing, and leading.

The selection of criteria used to measure the level of digital maturity in the CHR Kompas Gramedia refers to a research entitled An empirical investigation of employee portal success [6]. In his research, it was stated that the success rate of an employee portal or internal portal can be measured through the following dimensions:

a. System quality, considering performance, functionality, and system usage. System quality can be assessed by the level of ease of use of the system.

b. Information quality, focuses on the quality of information generated by the employee portal and useful for users.

c. Service quality, consisting of all support on the employee portal and the services provided. Related dimensions are responsiveness, reliability, empathy, and competence with personal service.

d. Use, measures the level of use of the employee portal used by company employees. There are several types of use, namely receiving and publishing information, communication, collaboration, networking, and executing work.

e. User satisfaction, measuring the affective attitude of employees who interact through the employee portal. The dimensions to be measured are adequacy, efficiency, effectiveness, and overall satisfaction with the portal.

f. Individual impact, which is the benefit that each individual gets when using the employee portal. The benefits include job performance, job efficiency, and overall usage.

g. Organization impact, measures related to quality progress, cost reduction and competitive advantage. 
h. Process quality, measures related to the quality of the employee portal process such as approvals, requests for leave, booking meeting rooms, submitting purchases of goods, registration time, travel expense reports, and invoice releases.

i. Collaboration quality, which measures the quality of the employee portal in support of collaboration between users. For example improving communication and increasing the effectiveness and efficiency of disseminating information.

j. Knowledge-intensity of task, measuring employees' understanding of a job.

k. Process standardization, employees usually do repetitive work and standardized work processes can affect the potential of the employee portal.

1. Management support, related to management support such as supervisors encouraging employees to use the portal.

\subsection{Customer Satisfaction}

According to Pavan \& Reddy; Christiana \& Rajan, internal customer satisfaction can be divided into 5 factors or components, namely, career development, the relationship between employees and managers, benefits and compensation schemes, a safe working environment, and engagement [2]. Stumpf stated that career development is one of the vital things that is managed by the HR department, renewed employee knowledge leads to job satisfaction. Singh suggests that managers should establish a strong, positive, and motivating communication policy between themselves and their staff through communication channels. Zulfqar; Lazar stated that employees perceive their performance and salary as a positive and significant relationship. Regarding the factors of a safe work environment, Wright and Davis examined the impact of the work environment on job satisfaction [2]. Based on job specificities, routines, feedback, and human resource development, it can be concluded that the work environment does lead to job satisfaction levels. Pavan and Reddy stated that employee satisfaction is very important to ensure the success of an organization. Employee satisfaction is closely related to employee engagement. Therefore according to Lazar, managers in an organization must ensure employee satisfaction, avoid low employee engagement, absenteeism and low productivity [2].

\subsection{Onboarding}

One way to increase employee engagement within a company is through the onboarding process. Onboarding can improve employee engagement and learning effectiveness, and can reduce costs and increase productivity [7]. Onboarding as the process of integrating and acculturating new employees into the organization and preparing work tools, resources, and knowledge to be successful and productive [8]. In addition, onboarding differs by orientation

One of the mistakes that can lead to failure to hire employees is due to a weak or inadequate onboarding process [9]. Companies that have weak onboarding processes are more likely to lose employees in their first year of employment. Onboarding is a process to help new employees adapt to the social environment and performance to new jobs quickly and precisely [10]. Effective onboarding for new employees is one of the important contributions a hiring or human resources manager can make in order to achieve long-term success in their organization [11]. Effective onboarding boosts new employee productivity, accelerates employee performance results, and significantly increases talent retention.

\subsection{QR Codes}

QR Code is the best choice to improve the experience in a company. QR code makes it easier for users to access content because it can be opened immediately and of course it is very cheap to change [12].

\section{Methodology and Data Analysis}

Therefore, based on research conducted by Urbach, Smolnik, and Riempp regarding employee portals, several indicators can be taken to measure the digital maturity level [6]. The indicators can be seen in the table 1 . 
Table 1. Digital Maturity Model.

\begin{tabular}{|c|c|c|c|}
\hline Dimension & Subdimension & Criteria & Reference \\
\hline \multirow[t]{6}{*}{ Customer } & Customer & Personalisation & Information quality \\
\hline & Engagement & Digital interactions & Service quality \\
\hline & Customer Insights and & Effortless & Use \\
\hline & Behaviour & Digital vision & User satisfaction \\
\hline & & Repetitive task & \\
\hline & & Journey continuity & \\
\hline \multirow[t]{7}{*}{ Strategy } & Ecosystem & Business models & Organization impact \\
\hline & Management & Relationship & Collaboration quality \\
\hline & Strategic Management & management & Management support \\
\hline & & On-boarding & \\
\hline & & Strategy alignment & \\
\hline & & Digital roadmap & \\
\hline & & Executive reporting & \\
\hline \multirow[t]{11}{*}{ Technology } & Emerging Technology & Standardized APIs & System quality \\
\hline & \& Application & Technology Roadmaps & Service quality \\
\hline & Data Management & Development & Process quality \\
\hline & Technology & Methodology & Process \\
\hline & Architecture & Big data platform & standardization \\
\hline & & Data model & \\
\hline & & Data lifecycle & \\
\hline & & Cloud & \\
\hline & & environment & \\
\hline & & Technology strategy & \\
\hline & & Platform & \\
\hline \multirow[t]{7}{*}{ Operations } & Real-time Insights and & Analytics & Process quality \\
\hline & Analytics & Insight trust & Process \\
\hline & Smart Process & Multi-discipline data & standardization \\
\hline & Management & team & \\
\hline & & Process Automation & \\
\hline & & Process evolution & \\
\hline & & Process data & \\
\hline \multirow[t]{7}{*}{ Organization Culture } & Leadership \& Culture & Leadership comms & Individual impact \\
\hline & Employee & Employee Impact & Knowledge-intensity \\
\hline & Enablement & Collaboration & of task \\
\hline & & Digital devices & \\
\hline & & Knowledge & \\
\hline & & Management & \\
\hline & & Talent development & \\
\hline
\end{tabular}

To measure the dimensions of the DMM, 33 criterias or indicators that are considered relevant with this DTP were chosen. Each indicators will be represented with one question and every question is given five options which is represents digital maturity level. There is an explanation in every options so that the respondent understands. The explanation are based on TM Forum DMM.

The questionnaires were distributed among employees. There are 38 respondents which is Kompas Gramedia employees. Validity testing uses the Pearson method. The criteria established to measure the validity or not is $r$ count greater than $r$-table at a significant rate of $5 \%$ or 0.05 . If the $r$-count is greater than the $r$-table, the measuring instrument does not meet the valid criteria [13]. The questionnaire is said to be reliable or reliable if the respondent's answer to the statement is consistent or stable over time, one of the reliability tests is to use the Cronbach's alpha method. The overall variable can be said that reliability is acceptable if it is greater than 0.6 [14].

The results of the questionnaire were confirmed to stakeholders. So stakeholders provide clarity about the current and future conditions. 


\section{Case Study}

Kompas Gramedia is a media company located in Jakarta which has a workforce of 23.329 in 2019. One of the strengths that Kompas Gramedia has is its strong brand, good credibility, and a wide network (Kompas newspaper, Gramedia store, Santika hotel, Amaris hotel, and regional newspaper Tribun which are spread all over Indonesia). The strength of Kompas Gramedia's Corporate Human Resources (CHR) is a complete recruitment process and talent management. Then, a complete and clear employee operational process. In addition, CHR implements the SAP Human Capital Management ERP system to support business processes. Then, CHR has MyKG and HR Portal which are internal platforms that can be accessed by all employees.

While the weakness in CHR is that there is no internal portal that provides information about Kompas Gramedia products for employees. In fact, employees are potential customers to buy and use company products. Therefore, employees still have to search the various websites or applications of each Kompas Gramedia product. Then, some business processes are still run manually, causing obstacles such as the onboarding process and attendance when attending an event. Collaboration tools that have not been standardized between business units make it difficult to collaborate. The difficulty of knowing each other's contacts is also an obstacle in the collaborative process. Digital technology transformation carried out is the integration of products and services owned by Kompas Gramedia into an internal platform, namely MyKG. Kompas Gramedia has products and services such as the Gramedia bookstore, Santika and Amaris hotels, magazines, Larisin, and Rekata. It is hoped that employees will find it easier to find information about Kompas Gramedia products and services. Also, employees can easily make transactions to buy these products and services

Furthermore, the digital technology transformation that will be carried out is also the process of onboarding which has so far been carried out face-to-face in a room and the speakers are leaders who deal with employees because it is to explain the work, regulations, and existing culture. It is hoped that digital transformation in the onboarding process will enable employees to find out complete, precise, and fast information about Kompas Gramedia. Then, each employee also runs the same onboarding process so that there are no material differences. Employees can also run the onboarding process on their first day of work.

Digital technology transformation that will also be carried out is the use of QR codes in the collaborative process of exchanging contacts where employees can directly scan QR codes through MyKG to find out other people's contacts. In addition, QR codes are also useful for attendance when attending events such as training.

\section{Research Result and Discussion}

Based on the results of the questionnaire and interview, which can be seen in Figure 1, there is a gap between the current digital maturity level and the future maturity level.

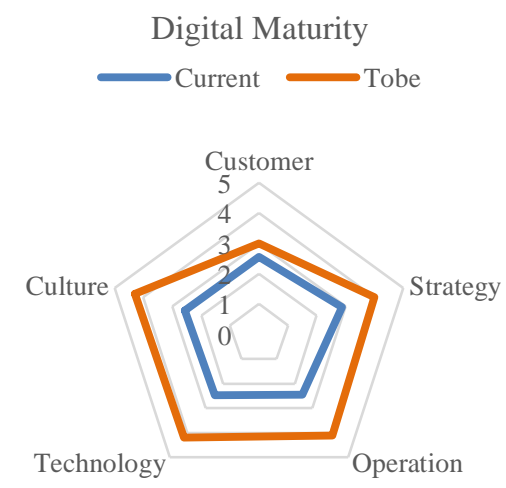

Fig. 1. Digital maturity current \& tobe. 
Table 2. Current \& future DMM level.

\begin{tabular}{lll}
\hline Dimension & Current DMM Level & Future DMM level \\
\hline Customer & Level 2 (emerging) & Level 3 (performing) \\
Strategy & Level 3 (performing) & Level 4 (advancing) \\
Technology & Level 2 (emerging) & Level 4 (advancing) \\
Operation & Level 2 (emerging) & Level 4 (advancing) \\
Culture & Level 2 (emerging) & Level 4 (advancing) \\
\hline
\end{tabular}

The target of the digital maturity level to be achieved during the next year shows that top management wants to develop the company through digital transformation.

The gap that arises from the current digital maturity level with the digital maturity level desired by stakeholders is the focus for the company. In order to achieve the target level of digital maturity that stakeholders want, a digital transformation is needed, namely MyKG and its features, such as integration of Kompas Gramedia products, onboarding, and QR codes. It is hoped that these features can improve employee digital experience and can also achieve the target digital maturity level.

\section{Conclusion}

MyKG is an internal platform specifically for Kompas Gramedia employees. MyKG aims to be the source of truth for all information in Kompas Gramedia. MyKG's digital transformation has transformed several processes from manual to digital, as well as providing benefits for companies in conveying information. MyKG digital transformation is carried out by referring to the five dimensions of the Digital Maturity Model, namely Customer, Strategy, Operation, Technology, and Organization.

Research related to the application of several features on MyKG saw several problems related to Kompas Gramedia's digital maturity level which is still at the performing level for the strategy dimension, as well as the emerging level for the customer, operation, technology, and organization dimensions. By implementing several features on $\mathrm{MyKG}$, it is hoped that it can increase the level of digital maturity of the company to suit the stakeholders' target. The features added to MyKG are the integration of Kompas Gramedia products, onboarding, and QR codes that can improve employee digital experience.

In this study, the company saw potential internal customers which is employees so that the integration of Kompas Gramedia products into MyKG was expected to increase product sales. In addition, the onboarding feature on MyKG can also provide cost savings from the manual process to digital process. Meanwhile, the $\mathrm{QR}$ Codes feature can improve employee collaboration in exchanging contact phone numbers or e-mails and can also improve the experience when participating in a company event by scanning QR Codes using MyKG as a sign of attendance.

\section{Implications / Limitations and Suggestions For Further Research}

This study has a research limitation, which is only examining several features that can improve employee digital experience through the internal platform. It is hoped that further research can examine other features that can improve employee digital experience through the internal platform and more respondents who filled out the questionnaire. Researchers also recommend further researchers to use or measure the level of digital maturity using different indicators so that they are expected to find other features that can be implemented. It is also hoped that other features will use technology that is better than current technology so that it can increase the company's digital maturity level from emerging and performing to leading levels.

\section{References}

[1] "Badan Pusat Statistik," www.bps.go.id.

https://www.bps.go.id/statictable/2009/04/16/970/penduduk-15-tahun-ke-atas-yang-bekerja-menurutlapangan-pekerjaan-utama-1986---2019.html. 
[2] J. Gomez, Relationship between Internal Customer Satisfaction and the External Customer Orientation in an IT Organisation". National College of Ireland: 2017.

[3] E. Lupfer, "Using The Employee Lifecycle As Your Roadmap To Employee Engagement Attraction Recruitment Onboarding Development Retention Separation." [Online]. Available: https://www.hr.com/en?t=/network/event/attachment.supply\&fileID=1418144677904.

[4] J. Morgan, The employee experience advantage : how to win the war for talent by giving employees the workspaces they want, the tools they need, and a culture they can celebrate. Hoboken, New Jersey: Wiley, 2017.

[5] U. Itam and N. Ghosh, "Employee Experience Management," International Journal of Human Capital and Information Technology Professionals, vol. 11, no. 2, pp. 39-49, Apr. 2020, doi: 10.4018/ijhcitp.2020040103.

[6] N. Urbach, S. Smolnik, and G. Riempp, "An empirical investigation of employee portal success," The Journal of Strategic Information Systems, vol. 19, no. 3, pp. 184-206, Sep. 2010, doi: 10.1016/j.jsis.2010.06.002.

[7] K. Depura and M. Garg, "Application of Online Gamification to New Hire Onboarding," 2012 Third International Conference on Services in Emerging Markets, Dec. 2012, doi: 10.1109/icsem.2012.29.

[8] P. for P. Service, "Getting On Board: A Model for Integrating and Engaging New Employees -, Partnership for Public Service. https://ourpublicservice.org/publications/getting-on-board-a-modelfor-integrating-and-engaging-new-employees/.

[9] M. Laurano, "The True Cost of a Bad Hire," 2015. [Online]. Available: https://b2bassets.glassdoor.com/the-true-cost-of-a-bad-hire.pdf.

[10] K. Becker and A. Bish, "A framework for understanding the role of unlearning in onboarding," Human Resource Management Review, p. 100730, Oct. 2019, doi: 10.1016/j.hrmr.2019.100730.

[11] G. B. Bradt, Onboarding: How to Get Your New Employees Up to Speed in Half the Time. John Wiley \& Sons, 2009.

[12] Dr. M. Stuit, "Business process innovation with QR Codes: A Case Study at the Dutch Archaeological Museum Hunebed Centre," University of Groningen. Netherland.

[13] I. Ghozali, Aplikasi Analisis Multivariate dengan Program SPSS. Badan Penerbit Universitas Diponegoro, Semarang: 2011.

[14] Uma Sekaran and R. Bougie, Research methods for business : a skill-building approach. Hoboken, Nj: John Wiley \& Sons, Inc, 2019. 